the Hospice of St Francis, 2012 bereaved adults "Cooking with Chris" programme, we developed a 5 -week teenagers course. This is a difficult age group to connect with. Food was used as a therapeutic bridge. Vital cooking skills were learnt and the experience and feelings of loss and grief addressed.

Bereaved teenagers between 11 and 18 years from the Hospice fortnightly 'drop in' took part. They had experienced the death of a close family member. Ideally, they attended with a significant adult.

After introductions and a practical induction to the hospice kitchen, weekly themed menus such as 'Amazing Mince' and 'Sausage Surprise' were produced. Undertaking the course was not without its challenges. There were no existing guidelines. One aspect was the emotional impact on the facilitators. A robust debriefing process was crucial for promoting understanding and resilience in the course staff and volunteers. Further anxiety was overcome about teens messing around if bored and how to control such behaviour in a busy working kitchen, whereas the previous adult groups have been very noisy, the teens were relatively quiet, probably as they were so busy concentrating!

Highlights included seeing the teens coming out of their shells and observing the parents working with the children. Parents found support in each other. Feedback commented how important it had been for their teen to come back to the hospice to do something enjoyable, adding positive memories to the sad ones she held of her Father dying there.

We believe that this programme provides innovative bereavement support for teenagers in a therapeutic, meaningful and fun way. Guidelines for others doing similar have been produced.

\section{P139 BUILDING CAPACITY AND COMPASSION: PILOTING A COLLABORATIVE PROJECT TO ENABLE YOUNG PEOPLE TO SUPPORT OTHERS WHO EXPERIENCE DEATH, BEREAVEMENT AND LOSS}

Nikki Archer, Pat Owen, Jane Beckett. St Giles Hospice, Lichfield, england

\subsection{6/bmjspcare-2013-000591.161}

St Giles Hospice has worked in collaboration with a local secondary school to pilot a 1 hour workshop for Year 8 pupils as part of their PSE programme. The work shop was accredited by Education Transformation, Staffordshire Education Authority and was facilitated by trained volunteers. Students were invited to create a young person through whom they were able to explore issues relating to death, bereavement and loss. Over 200pupils participated.

Peer support is a key aspect of the support young people identify as being helpful in enabling them to adapt and cope with bereavement. Building capacity and compassion within our community is a key strategic aim.

Evaluation A number of key themes were identified from the students feedback. The students felt it enabled them to:

- listen to each other

- understand others feelings

- respecting difference

- talk safely about death, bereavement and loss.

- understand the impact on the listener

Only 5 students stated they felt they had gained nothing from the session

The facilitators feedback indicated that generally students were:
- engaged and eager to share their ideas and experiences.

- enabled to understand issues relating to death, bereavement and loss.

- enabled to identify how they might support a friend who had suffered a loss

The role of the teacher and the need for the practicalities to have been agreed was highlighted.

Teachers feedback indicated that the workshop was well delivered, helpful and informative giving an opportunity for young people to understand the issues.

The project forms part of the Hospice's programme for building compassion and capacity within our local community. Additional opportunities for fundraising and volunteering were identified. We plan to build on the success of the project by exploring opportunities to work in partnership with other local organisations to deliver the workshops.

\section{P140 KYLIE, JASON, CHANTELLE AND JESS: CREATING CHARACTERS AS A CATALYST FOR CHANGE. ENABLING THE COMMUNITY TO UNDERSTAND AND MEET THE NEEDS OF YOUNG PEOPLE EXPERIENCING LOSS AND BEREAVEMENT}

${ }^{1}$ Nikki Archer, ${ }^{2} J e n n i$ Coleman, 'Carol Rodgers, ${ }^{1}$ Helen Chetwynd. 'St Giles Hospice, Lichfield, England, '2 Lichfield Disrict Safer Community Partnership

10.1136/bmjspcare-2013-000591.162

A collaborative project between St Giles Hospice and Lichfield District Safer Community Partnership was undertaken which aimed to

- build sustained confidence and capacity of community staff to enable them to help and support young people who are coping with loss and bereavement.

- For children and young people within our local community to be better supported and understood through their loss experiences

There is strong evidence that bereavement and the changes that accompany it can make children and young people vulnerable to poor outcomes, particularly in disadvantaged circumstances. Many children and young people are able to accommodate and adjust to their loss if they receive the right help and support through their usual networks, however, those who work with young people tell us they feel ill equipped to support young people who have experienced loss and bereavement.

During a half day workshop participants were afforded an opportunity to explore death, dying, bereavement and loss through the creation of a character based within their own experiences.

Pre and post workshop participants were asked to rate how confident they felt

- talking to young people about death and dying?

- supporting a young person who has been bereaved?

The results were very positive.

- 58 attended

- $94 \%$ assessed themselves with a higher post workshop score, the average score increased from 5 to 8 for both questions. All valuedthe workshop.

- A follow up focus group was held 9 months after the initial workshop. Feedback demonstrated the ripple effect the workshop had ona personal and professional 